\title{
Morfologia da germinação de sementes de Senna cana (Nees \& Mart.) H.S. Irwin \& Barneby ${ }^{1}$ \\ Jordânia Xavier de MEDEIROS ${ }^{2 *}$, Ana Lícia Patriota FELICIANO² ${ }^{2}$ Jamile Erica de MEDEIROS², Helder Henrique Duarte SANTOS ${ }^{2}$, Valderez Pontes MATOS ${ }^{2}$
}

\author{
${ }^{1}$ Trabalho selecionado no VI Congresso Nordestino de Engenharia Florestal, Mossoró, RN, Brasil. \\ ${ }^{2}$ Universidade Federal Rural de Pernambuco, Recife, Pernambuco, Brasil. \\ *E-mail: jordaniamedeiros@hotmail.com
}

\begin{abstract}
Recebido em maio/2019; Aceito em junho/2019.
RESUMO: O objetivo do estudo foi descrever a morfologia da germinação de plântulas normais de Senna cana (Nees \& Mart.) H. S. Irwin \& Barneby e, descrever as plântulas anormais. A coleta das sementes foi realizada no Parque Nacional Vale do Catimbau, Buíque - PE. As sementes foram escarificadas, desinfestadas e lavadas com água deionizada. Foram utilizadas quatro repetições de 25 sementes, semeadas sobre papel toalha e postas para germinar em B.O.D a $20-30^{\circ} \mathrm{C}$. A emissão da radícula ocorreu no terceiro dia após semeadura, coloração bege amarelada, tenra, cilíndrica, com pelos radiculares. Do $7^{\circ}$ ao $11^{\circ}$ dia, alongamento do hipocótilo e surgimento das raízes secundárias. O hipocótilo cilíndrico, herbáceo, coloração amarela, com tricomas curtos. No $17^{\circ}$ dia, o surgimento do epicótilo pubescente. Aos 45 dias, o sistema radicular pivotante, com comprimento de 3,0 a 3,5 $\mathrm{cm}$ de coloração marrom enegrecida. O hipocótilo de 2,5 a 3,0 cm, cilíndrico, reto ou tortuoso, verde-claro no ápice e amarelado na base. Cotilédones persistentes, limbo levemente pendente, verde-escuro em ambas as faces e nervação evidente. Os protófilos compostos, pinados, alternos, peciolados, verde-claro, com dois folíolos e muitos tricomas. A semente de $S$. cana apresenta germinação epígea, sendo as plântulas classificadas como fanerocotiledonares.
\end{abstract}

Palavras-chave: Caatinga; estudo morfológico; espécie nativa.

\section{Morphology of seed germination of Senna cana (Nees \& Mart.) H.S. Irwin \& Barneby}

\begin{abstract}
The objective of the study was to describe the germination morphology of normal seedlings of Senna cana (Nees \& Mart.) H. S. Irwin \& Barneby and, describe the abnormal seedlings. The seeds were collected in the Vale do Catimbau National Park, Buíque - PE. The seeds were scarified, disinfested and washed with deionized water. Four replicates of 25 seeds were used, sown on paper towel and put to germinate in B.O.D at $20-30^{\circ} \mathrm{C}$. The emission of the radicle occurred on the third day after sowing, beige yellowish color, tender, cylindrical, with root hairs. From 7th to 11th day, hypocotyl elongation and secondary root development. The cylindrical hypocotyl, herbaceous, yellow color, with short trichomes. On the 17 th day, the appearance of the pubescent epicotyl. At 45 days, the pivotal root system, with 3.0 to $3.5 \mathrm{~cm}$ length of blackish brown coloration. Hypocotyl 2.5-3.0 cm, cylindrical, straight or tortuous, light green at apex and yellow at base. Persistent cotyledons, slightly pendulous limb, dark green on both cheeks and obvious veining. The prototyphs composed, pinnate, alternate, petiolate, light green, with two leaflets and many trichomes. The $S$. cana seed presents epigene germination, the seedlings being classified as phanerocotonares.
\end{abstract}

Keywords: Caatinga; morphological study; native species.

\section{INTRODUÇÃO}

Os estudos morfológicos envolvendo sementes e frutos vêm sendo conduzidos há muito tempo e, alguns pesquisadores apontam Gaertner (1791) como o primeiro a estudar mais detalhadamente a morfologia do fruto e da semente de diversas famílias, incluindo a Fabaceae, representando conforme Lima et al. (2014) um dos grupos mais importantes das espermatófitas, com 727 gêneros e 19.325 espécies.

Entre as sementes e frutos, há uma grande diversidade em relação aos aspectos externos e internos, relacionados ao tamanho, estrutura, cor do tegumento, presença de endosperma, que irão auxiliar na compreensão tanto das estratégias de dispersão como na germinação, representando também, caracteres de grande importância para a delimitação dos gêneros de muitas famílias e subfamílias. Contudo, no
Brasil, estudos sobre as características morfológicas de sementes, bem como da germinação e de plântulas de espécies nativas florestais são escassos, se comparados à diversidade da flora brasileira (COSMO et al., 2009).

O tipo de germinação representa um dos caracteres mais relevantes para diferenciar espécies, enquanto o conhecimento morfológico da plântula, especialmente a forma do limbo, da margem, do ápice, posição dos protófilos, presença ou ausência de látex ou resina, relação comprimento/largura dos cotilédones, tamanho das pinas, número de pinas, pecíolo alado ou não, presença ou não de indumento (tricomas e/ou glândulas), permitem caracterizar famílias, gêneros e espécies (GURGEL et al., 2012). Bem como, o enfoque na descrição morfológica de plântulas e plantas jovens é importante no esclarecimento de questões relativas à taxonomia, ecologia $\mathrm{e}$ filogenia, e constituem ferramenta de identificação, as quais 
ocorrem frequentemente em estudos relacionados com o desenvolvimento da vegetação.

Desse modo, o reconhecimento morfológico das espécies nas fases iniciais de vida agrega valores importantes para a taxonomia de diversos grupos vegetais, pois amplia a quantidade de informações morfológicas que podem ser utilizadas em conjunto com os caracteres tradicionalmente empregados para a identificação das espécies, proporcionando maiores chances para a correta identificação, sobretudo das espécies florestais (GURGEL et al., 2012).

A Senna cana (L.) H.S Irwin \& Barneby (Fabaceae Caesalpinioideae), nativa, não endêmica do Brasil é considerada espontânea em área de Caatinga, Campo Rupestre, Cerrado, Vegetação sobre Afloramentos Rochosos (SOUZA; BERTOLUZZI, 2015). Apresenta potencial medicinal, constituindo-se em fonte promissora de antioxidantes naturais (MONTEIRO, 2012). Classificada como espécie perenifólia episódica, com eventos reprodutivos sazonais e altamente sincrônicos (floração intermediária no período chuvoso e frutificação longa no período seco) e tais características na floração, somadas à síndrome de melitofilia, configuram importantes estratégias para atração de potenciais polinizadores (SOUZA et al., 2012).

A descrição morfológica com espécies de Senna foi realizada por alguns autores, destacando-se os trabalhos com a morfologia de frutos, sementes (PINTO, 2013), plântulas e mudas (AMORIM et al., 2008) de Senna multijuga e Gurgel et al. (2014), descreveram a morfologia dos frutos e das sementes de Senna obtusifolia (L.) H. S. Irwin \& Barneby, S. occidentalis (L.) Link. e S. tapajozensis (Ducke) H. S. Irwin \& Barneby.

Considerando a carência de estudos e a importância ecológica de $S$. cana, o trabalho teve como objetivo descrever os aspectos morfológicos das fases da germinação e, as categorias de plântulas normais e anormais da mesma.

\section{MATERIAL E MÉTODOS}

\subsection{Escolha das matrizes de Senna cana}

Foram selecionadas 11 matrizes de $S$. cana, baseando-se nas recomendações descritas por Oliveira (2012), selecionando-se os indivíduos quanto ao porte, forma da copa, forma do tronco (com pouca tortuosidade), fitossanidade (ausência de doenças e/ou pragas), boa produção de sementes (presença de muitas flores) e a distância mínima de $50 \mathrm{~m}$ entre os mesmos, visando diminuir a possibilidade de se utilizar indivíduos idênticos geneticamente (Figura 1).

Para confirmação das informações taxonômicas da espécie e confecção de exsicatas, foi coletado material botânico fértil das matrizes. As amostras foram incorporadas, sob o número 21718, ao Herbário Sérgio Tavares (HST), do Departamento de Ciência Florestal, da Universidade Federal Rural de Pernambuco.

Os frutos foram coletados diretamente da copa de cada matriz antes da abertura espontânea das primeiras vagens e, acondicionados em sacos plásticos preto, devidamente identificados. Posteriormente, transportados para o Laboratório de Sementes do Departamento de Agronomia da UFRPE, em Recife-PE, e submetidos ao beneficiamento para extração das sementes. As matrizes foram georreferenciadas (Tabela 1), a fim de facilitar coletas posteriores de sementes, seja para a produção de mudas, pesquisas acadêmicas ou outras finalidades. $\mathrm{O}$ banco de dados foi georreferenciado ao
Sistema Geodésico SIRGAS 2000 e à Projeção Cartográfica UTM (Zona 24S).

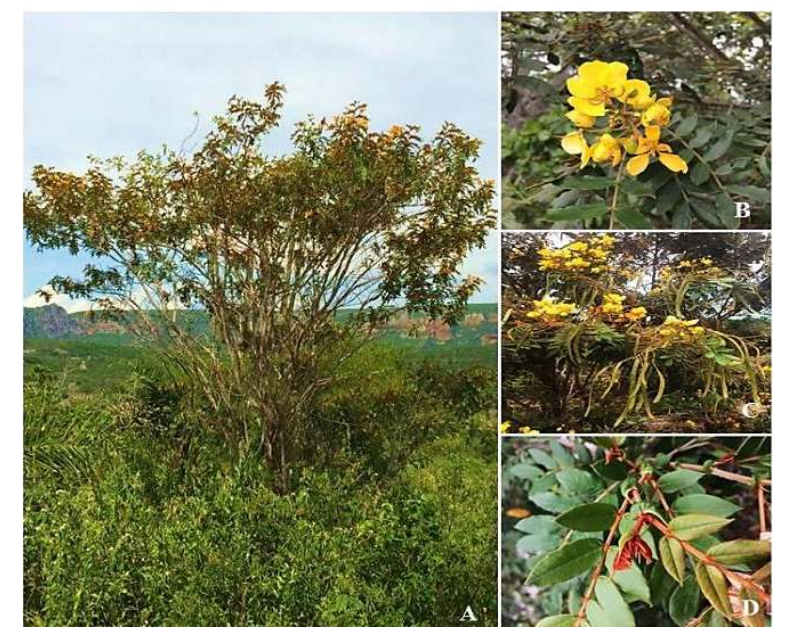

Figura 1. Registro fotográfico da espécie arbustiva Senna cana $\mathrm{H}$. S Irwin \& Barneby (A); Detalhes das flores, frutos e folhas compostas; estípulas (B, C, D), ocorrentes no Vale do Catimbau, Buíque - PE. Figure 1. Photographic record of the shrub species Senna cana H. S. Irwin \& Barneby (A); Details of flowers, fruits and leaves composite; stipules (B, C, D), occurring in the Catimbau Valley, Buíque - PE.

Tabela 1. Coordenadas geográficas (UTM) das matrizes de Senna cana (Nees \& Mart.) H.S. Irwin \& Barneby, selecionada no Parque Nacional do Catimbau em Buíque - PE.

Table 1. Geographic coordinates (UTM) of Senna cana matrices (Nees \& Mart.) H.S. Irwin \& Barneby, selected in the Catimbau National Park in Buíque - PE.

\begin{tabular}{ccc}
\hline \multirow{2}{*}{ Matrizes } & \multicolumn{2}{c}{ Coordenadas Geográficas (UTM) } \\
\cline { 2 - 3 } & Latitude (Oeste) & Longitude (Sul) \\
\hline M1 & 692330 & 9056446 \\
M2 & 692434 & 9056501 \\
M3 & 692473 & 9056373 \\
M4 & 692439 & 9056324 \\
M5 & 692417 & 9056298 \\
M6 & 692371 & 9056308 \\
M7 & 692325 & 9056340 \\
M8 & 692427 & 9055584 \\
M9 & 692108 & 9053462 \\
M10 & 692081 & 9053371 \\
M11 & 691867 & 9053103 \\
\hline
\end{tabular}

\subsection{Morfologia da germinação e plântulas}

As sementes de Senna cana foram semeadas em rolos de papel toalha (cobertas com saco plástico transparente para reduzir a perda de água), com quatro repetições de 25 sementes, umedecidos em solução de nistatina a $0,2 \%$, na proporção de 2,5 vezes o peso do papel seco, conforme recomendação das Regras para Análise de Sementes (BRASIL, 2009b). Em seguida, foram postas em germinador tipo Biochemical Oxigen Demand (B.O.D.), regulado à temperatura alternada de $20-30^{\circ} \mathrm{C}$, com luz contínua proveniente de lâmpadas fluorescentes tipo luz do dia (4 x 20 W). Antes da semeadura, as sementes foram desinfestadas com solução de hipoclorito de sódio a $5 \%$, por cinco minutos, em seguida, lavadas com água deionizada.

As plântulas tiveram seu crescimento acompanhado no substrato papel toalha anotando-se e fotografando-se todos os detalhes morfológicos externos, durante dezessete dias. Após este período, para promover mais espaço ao desenvolvimento 
da raiz e parte aérea, as plântulas mais vigorosas foram transplantadas para bandejas plásticas $(20 \times 10 \times 10 \mathrm{~cm})$ contendo como substrato areia, até o surgimento dos protófilos (quarenta e cinco dias após semeadura).

Para as descrições morfológicas dos caracteres utilizaramse as plântulas normais mais vigorosas, com auxílio de fotografias e ilustrações realizadas manualmente, e os detalhes observados com auxílio de lupa binocular e microscópio estereoscópico binocular. As plântulas anormais que apresentaram ausência ou deformidade de uma ou mais estruturas essenciais também foram descritas, caracterizadas, ilustradas e fotografadas.

\subsection{Critérios para definição de categorias de plântulas normais e anormais}

No final do teste de germinação, para determinação da morfologia das plântulas e fases da germinação foram identificadas, caracterizadas, e ilustradas, as plântulas normais capazes de produzirem plantas com todas as suas estruturas essenciais e as plântulas anormais que apresentaram ausência ou deformidade de uma ou mais estruturas essenciais, de acordo com Brasil (2009b).

\section{RESULTADOS}

3.1. Morfologia da germinação e descrição das plântulas normais

Senna canna (Nees \& Mart.) H.S. Irwin \& Barneby

Família: Fabaceae

Subfamília: Caesalpinioideae

Após intumescimento da semente, a testa pode ou não sofrer uma leve descamação. A radícula foi verificada no terceiro dia após semeadura, com rompimento do tegumento na região basal da semente (Figura 2A) que apresentou coloração bege amarelada, tenra, cilíndrica, com pelos radiculares simples, finos, hialinos, tenros, brilhantes, tornando-se, com o desenvolvimento, afinada da base para o ápice; coifa não evidente.

Do sétimo ao décimo primeiro dia (Figura 2B-C), houve alongamento do hipocótilo, que no início do desenvolvimento apresentou aspecto geniculado, passando rapidamente para ereto, erguendo acima do solo, os cotilédones envolvidos no tegumento, com coloração bege esbranquiçada, muitos tricomas, curtos e hialinos. O coleto é curto, cilíndrico e esbranquiçado, delimitado pela abundante pilosidade que marca o início da radícula; alongamento gradativo da raiz principal, com coloração marrom e surgimento de raízes secundárias, finas e escassas, de coloração bege.

A partir do décimo quarto dia (Figura 2D), o tegumento se desprendeu dos cotilédones, que se apresentaram verdes, coriáceos, opostos, peciolados, oblongos, com ápice obtuso ou arredondado, base ligeiramente truncada e bordos inteiros, com nervação trinérvea evidente; O hipocótilo apresentou-se cilíndrico, herbáceo, de coloração amarela esbranquiçada, com tricomas curtos, brilhantes e hialinos; alongamento da raiz principal e surgimentos de mais raízes secundárias, com alguns tricomas, hialinos, brilhantes, de coloração rufo.

No décimo sétimo dia (Figura 2E), tem-se o surgimento do epicótilo pubescente, ainda pequeno, em forma de nó, com muitos tricomas simples, finos, curtos, macios, brilhantes e hialinos.

Aos 45 dias após semeadura (Figura 3), o sistema radicular pivotante, com raiz axial bastante desenvolvida, apresentou comprimento de 3,0 a 3,5 cm, coloração marrom enegrecida e raízes secundárias um pouco hialinas, marrom-claro, com muitos tricomas. $\mathrm{O}$ hipocótilo com comprimento médio de 2,5 a 3,0 cm é cilíndrico, reto ou tortuoso, brilhante, verde-claro no ápice e amarelado na base, com tricomas finos, curtos e hialinos, estreito na base, próximo à região do coleto e pulvino no ápice, próximo à inserção dos cotilédones.

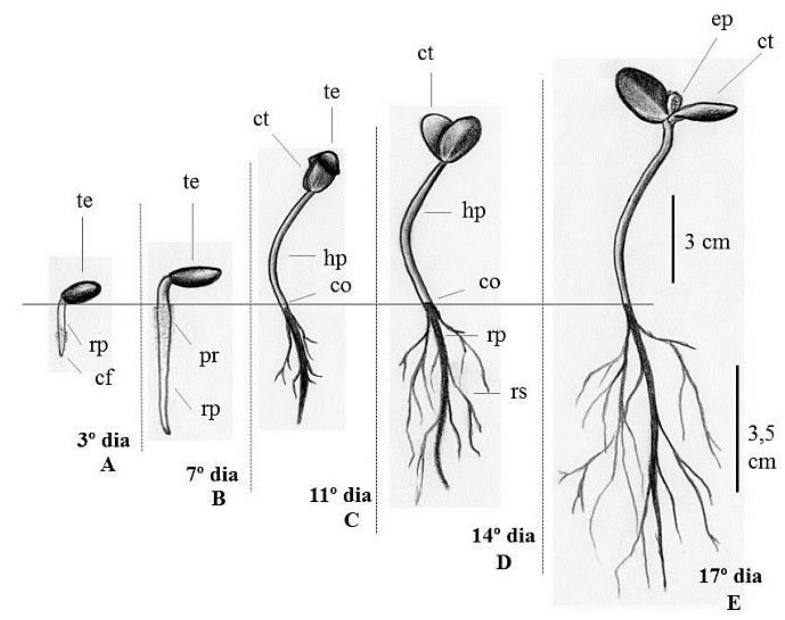

Figura 2. Fases da germinação e formação da plântula de Senna cana (Nees \& Mart.) H.S. Irwin \& Barneby. A, B, C - fases de desenvolvimento em que o tegumento encontra-se aderido aos cotilédones e alongamento gradual da raiz principal; alongamento do hipocótilo e da raiz principal, com; D - desenvolvimento das raízes secundárias e expansão dos cotilédones; E - início do desenvolvimento do epicótilo; F - plântula normal. (rp - raiz principal, cf - coifa; $\mathrm{pr}$ - pelos radiculares; te - tegumento, ct - cotilédones, hp - hipocótilo, co - coleto, rs - raízes secundárias; ep - epicótilo, pt protófilos, ga - gema apical).

Figure 2. Stages of germination and seedling formation of Senna cana (Nees \& Mart.) H.S. Irwin \& Barneby. A, B, C - stages of development in which the integument is adhered to the cotyledons and gradual stretching of the main root; elongation of the hypocotyl and the main root, with; D - development of secondary roots and expansion of cotyledons; E - onset of epicotyl development; F normal seedling. (rp - main root, cf - coifa, prostrates, te - tegument, ct - cotyledons, hp - hypocotyl, co - collection, rs - secondary roots, ep - epicotyl, pt - prophyphiles, ga - apical gait).

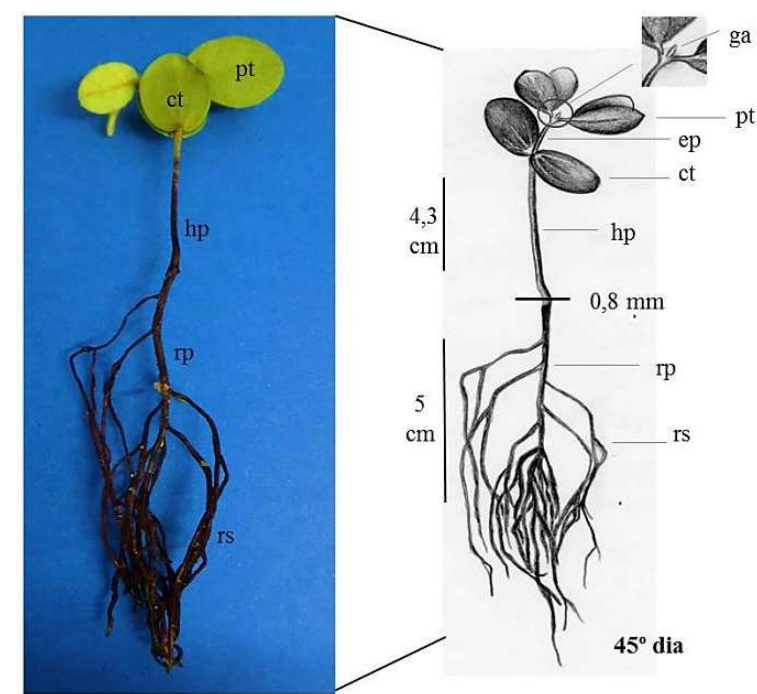

Figura 3. Formação da plântula normal de Senna cana (Nees \& Mart.) H.S. Irwin \& Barneby, aos 45 dias após semeadura (ga - gema apical; pt - protófilos; ct - cotilédones; ep - epicótilo; hp - hipocótilo; rp raiz principal; $r$ - raízes secundárias). 
Figure 3. Formation of the normal seedling of Senna cana (Nees \& Mart.) H.S. Irwin \& Barneby, at 45 days after sowing (apical gait, protophylls, ct - cotyledons, ep - epicotyl, hp - hypocotyl, rp - main root, rs - secondary roots).

Os cotilédones são persistentes, com limbo levemente pendente, verde-escuro em ambas as faces, com nervação evidente, medindo em torno de 1,0 a $1,4 \mathrm{~cm}$ de comprimento e 0,8 a 1,0 de largura. O epicótilo pubescente, cilíndrico, verde-claro, brilhante, com tricomas curto, muito fino, brilhante, tortuoso, com duas colorações, um mais hialino no pecíolo e o outro de coloração cinéreo-rufo próximo às extremidades dos protófilos e na gema apical. O pecíolo é curto, pubescente, cilíndrico, e verde-claro.

Os protófilos são compostos, pinados, alternos, peciolados, verde-claro, com dois folíolos e bastante pelos translúcidos e glandulares de coloração ferrugínea, apresentando aumento no número de pares de folíolos à medida que novas folhas vão surgindo. As plântulas apresentam um rápido desenvolvimento do epicótilo e uma acelerada formação e expansão de novas folhas.

\subsection{Descrição morfológica das plântulas anormais}

As anormalidades foram observadas antes da emissão dos protófilos.

Dessa forma, foram observados cinco tipos de anormalidades (Figura 4): atrofiamento da raiz principal, desenvolvimento apenas dos cotilédones e hipocótilo; torção da raiz principal; cotilédones necrosados; hipocótilo pouco desenvolvido, grosso e curto; torção do hipocótilo e radícula.

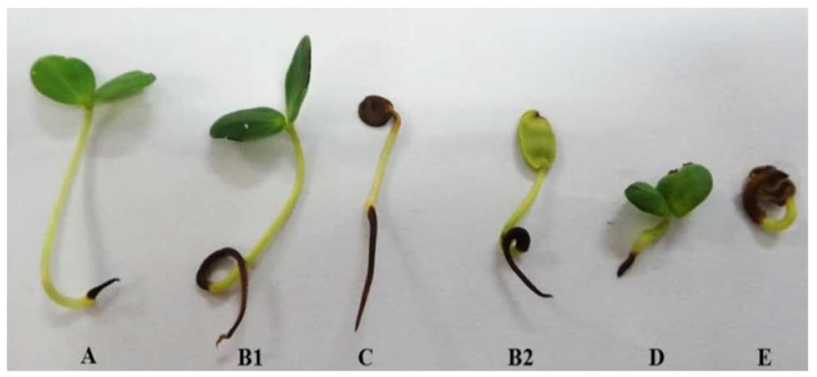

Figura 4. Plântulas anormais de Senna cana (Nees \& Mart.) H.S. Irwin \& Barneby: A - desenvolvimento apenas do hipocótilo e cotilédones, raiz desproporcional em relação às outras estruturas da plântula; B 1,2 - enrolamento da raiz principal; C - cotilédones necrosados; D - hipocótilo curto, grosso e raiz atrofiada; E hipocótilo curto e curvado sobre si e enrolamento da raiz principal. Figure 4. Abnormal seedlings of Senna cana (Nees \& Mart.) H.S Irwin \& Barneby: A - development only of hypocotyl and cotyledons, root disproportionate to other structures of the seedling; B 1,2 - main root winding; $\mathrm{C}$ - necrotic cotyledons; D - short, thick hypocotyl and atrophied root; E - hypocotyl short and curved over itself and winding the main root.

\section{DISCUSSÃO}

Em virtude do tipo de germinação da semente e da emergência da plântula, a germinação da semente de $S$. cana foi classificada como fanerocotiledonar, caracterizando-se por expor os cotilédones, os quais ficam livres do tegumento da semente, e epígea, pois os cotilédones permaneceram sob a superfície da areia.

A germinação fanerocotiledonar também foi descrita para espécies pertencentes à família Fabaceae, a exemplo de Poincianella pyramidalis (MENDONÇA et al., 2016); Guibourtia hymenifolia (BATTILANI et al., 2011); Dalbergia cearenses (NOGUEIRA et al., 2010); Senna multijuga (AMORIM et al., 2008) e Myracrodruon urundeuva Allemão (FELICIANO et al., 2008).

De acordo com Feliciano et al. (2008), uma das razões que justificam esta semelhança na germinação está relacionada ao sistema fisiológico inerente a espécie, servindo como mecanismo de sobrevivência e adaptação quando germinadas.

Conforme Barroso et al (1999), o eixo hipocótilo-radícula é sempre reto em Caesalpinioideae, porém $S$. cana demonstrou eixo as vezes oblíquo, diferentemente da descrição dos autores, porém corroborando com os resultados observados por Gurgel et al. (2014) para S. tapajozensis.

Os resultados dos testes de avaliação do tipo de germinação e desenvolvimento da plântula possibilitaram estabelecer critérios para plântulas normais: raiz primária, raízes secundárias, hipocótilo, epicótilo, cotilédones e protófilos, desenvolvidos e equilibrados quanto ao desenvolvimento e sem alterações de outra natureza, ao passo que, para as plântulas anormais: desenvolvimento do hipocótilo e, ou, da raiz primária insuficientes para o desenvolvimento subsequente da plântula, durante o período de avaliação do teste de germinação.

As plântulas anormais são aquelas que mesmo em condições favoráveis, não demonstram potencial para continuar seu desenvolvimento e dar origem a plantas normais, podendo ser classificadas como: danificadas, deformadas e deterioradas (BRASIL, 2009a).

Dessa forma, as características morfológicas da germinação e desenvolvimento da plântula, fornecem informações que permitem a identificação de espécies em fases juvenis e tal conhecimento é indispensável quando se pretende por exemplo, compreender o ciclo biológico e a regeneração natural das espécies.

\section{CONCLUSÕES}

A germinação é epígea-fanerocotiledonar. A germinação epígea, tem início no $3^{\circ}$ dia com protusão da radícula e, aos 45 dias, têm-se a plântula com todas as estruturas essenciais, classificada como fanerocotiledonar.

\section{AGRADECIMENTOS}

À Coordenação de Aperfeiçoamento de Pessoal de Nível Superior $(C A P E S)$ pelo financiamento da pesquisa.

\section{REFERÊNCIAS}

AMORIM, I. L.; DAVIDE, A. C.; FERREIRA, R. A.; CHAVES, M. M. F. Morfologia de frutos, sementes, plântulas e mudas de Senna multijuga var. lindleyana (Gardner) H. S. Irwin \& Barneby - Leguminosae Caesalpinioideae. Revista Brasileira Botânica, São Paulo, v. 31, n. 3, p. 507-516, 2008.

BARROSO, G. M.; MORIM, M. P.; PEIXOTO, A. L.; ICHASO, C. L. F. Frutos e sementes: morfologia aplicada à sistemática de dicotiledôneas. Viçosa: UFV, 1999. 443p

BATTILANI, J. L.; SANTIAGO, E. F.; DIAS, E. S. Morfologia de frutos, sementes, plântulas e plantas jovens de Guibourtia hymenifolia (Moric.) J. Leonard (Fabaceae). Revista Árvore, Viçosa, v. 35, n. 5, p. 1089-1098, 2011. DOI: http://dx.doi.org/10.1590/S010067622011000600015

BRASIL MINISTÉRIO DA AGRICULTURA, PECUÁRIA E ABASTECIMENTO; SECRETARIA DE DEFESA 
AGROPECUÁRIA. Glossário ilustrado de morfologia Mapa/ACS, Brasília, Brasil. 2009a. 406 p.

BRASIL MINISTÉRIO DA AGRICULTURA, PECUÁRIA E ABASTECIMENTO. Regras para análise de sementes. Brasília: MAPA/ACS, 2009b. 395 p.

COSMO, N. L.; GOGOSZ, A. M.; NOGUEIRA, A. C.; BONA, C.; KUNIYOSHI, Y. S. Morfologia do fruto, da semente e morfo-anatomia da plântula de Vitex megapotamica (Spreng.) Moldenke (Lamiaceae). Acta Botanica Brasilica, Belo Horizonte, v. 23, n. 2, p. 389397, 2009. DOI: http://dx.doi.org/10.1590/S010233062009000200010

FELICIANO, A. L. P.; MARANGON, L. C.; HOLANDA, A. C. Morfologia de sementes, de plântulas e de plântulas jovens de aroeira (Myracrodruon urundeuva Allemão). Revista de Biologia e Ciências da Terra, Paraíba, v. 8, n. 1, p. 198-206, 2008.

GURGEL, E. S. C.; SILVA, M. F.; LUCAS, F. C. A.; CARREIRA, L. M. M.; SANTOS, J. U. M. dos. Morfologia do fruto e da semente de três espécies de Senna Mill. (Leguminosae - Caesalpinioideae). Biota Amazônia, Macapá, v.4, n.2, p.80-86, 2014.

GURGEL, E. S. C.; SANTOS, J. U. M.; LUCAS, F. C. A.; BASTOS, M. N. C. Morfologia de plântulas de Leguminosae e o potencial sistemático. Rodriguésia, Rio De Janeiro, v. 63, n. 1, p. 65-73, 2012. DOI: http://dx.doi.org/10.1590/S2175-78602012000100006

MENDONÇA, A. V. R.; FREITAS, T. P. S.; SOUZA, L. S.; FONSECA, M. D. S.; SOUZA, J, S. Morfologia de frutos e sementes e germinação de Poincianella pyramidalis (Tul.) L. P. Queiroz, comb. Nov. Ciência Florestal, Santa
MONTEIRO, J. A. Estudo químico e farmacológico de Senna cana H.S. Irwin \& Barneby. 2012. $106 f$. Dissertação (Mestrado em Química Orgânica) Universidade Federal do Ceará, Fortaleza, 2012.

NOGUEIRA, F. C. B.; MEDEIROS, FILHO, S.; GALLÃO, M. I. Caracterização da germinação e morfologia de frutos, sementes e plântulas de Dalbergia cearensis Ducke (pauvioleta) - Fabaceae. Acta Botânica Brasilica, Belo Horizonte, v. 24, n. 4, p. 978-985, 2010. DOI: http://dx.doi.org/10.1590/S0102-33062010000400013

OLIVEIRA, O. S. Tecnologia de sementes florestais: espécies nativas. Curitiba: Editora da UFPR, 2012. 404 p.

PINTO, T. T. Morfoanatomia e fisiologia de sementes com dormência física de Colubrina glandulosa perkins (rhamnaceae) e Senna multijuga (rich.) h. s. Irwin \& Barneby (Caesalpinioideae - Fabaceae). 2013. $17 \mathrm{f}$. Dissertação (Mestrado em Biologia Vegetal) Universidade Federal de Santa Catarina, Centro de Ciências Biológicas, Florianópolis, 2013.

SILVA, L. F.; BERTONI, J. E. A.; COSTA, A. M. M.; MATTHEUS, L. A. F. Arborização viária urbana: espécies de pequeno porte com potencial de uso. Revista Brasileira de Horticultura Ornamental, Campinas, v.11, n.1, p.1320, 2005. DOI: https://doi.org/10.14295/rbho.v11i1.7

SOUZA, V. C.; BORTOLUZZI, R. L. C. Senna in: Lista de Espécies da Flora do Brasil. Jardim Botânico do Rio de Janeiro. 2015.

SOUZA, I. M.; COUTINHO, K.; FUNCH, L. S. Estratégias fenológicas de Senna cana (Nees \& Mart.) H.S. Irwin \& Barneby (Fabaceae: Caesalpinioideae) como mecanismo eficiente para atração de polinizadores. Acta Botanica Brasilica, Belo Horizonte, v. 26, n. 2, p. 435-443, 2012. DOI: http://dx.doi.org/10.1590/S0102DOI: http://dx.doi.org/10.5902/1980509822738 